\title{
Effect of incorporation of lignin as bio-polyol on the performance of rigid lightweight wood- polyurethane composite foams
}

Shupin Luo ${ }^{1,2}$, Li Gao ${ }^{1,2^{*}}$ and Wenjing Guo $0^{1,2}$

\begin{abstract}
Density reduction has become a topical issue in wood composite materials for application in building and furniture. In this study, lightweight wood-polyurethane (W-PU) composite foams with the addition of $30 \mathrm{wt} \%$ wood particles were prepared. Industrial kraft lignin was used as bio-polyol to substitute partial petroleum-based diethylene glycol (DEG) to synthesize rigid W-PU foams. The effect of varying lignin contents $(5,10,15$ and 20 wt $\%$ based on DEG mass) on the reactivity, morphology, density, compressive properties, water absorption and thermal stability of the foams was evaluated. Fourier transform infrared (FTIR) analysis confirmed the formation of characteristic urethane linkages in all the foam samples. With the incorporation of lignin, the foam cellular shape became irregular with formation of large cells. W-PU foams exhibited poor cellular structures with a larger number of open cells. The density of W-PU foams increased from 47 to $96 \mathrm{~kg} / \mathrm{m}^{3}$ as the lignin content increased from 0 to $20 \%$. Although the foam reactivity was decreased by the incorporation of lignin, both the compressive strength and modulus were increased upon the incorporation of lignin. Furthermore, the specific compressive strength and modulus of W-PU foams increased by $55 \%$ and $48 \%$ with lignin content increasing from 0 to $20 \%$, and the 20 -day water absorption decreased by $38 \%$. Thermal gravimetric analysis showed that the incorporation of lignin did not significantly affect the thermal degradation behaviour of foam, but it rather increased the mass of char residue. This study provides a promising method for value-added utilization of technical lignin in W-PU lightweight composites.
\end{abstract}

Keywords: Wood, Lignin, Polyurethane, Lightweight composite, Compressive properties

\section{Introduction}

Nowadays, density reduction has become a topical issue in wood-based composite industry for application in building and furniture [1-3]. The lightweight wood-based panels are desirable for both economic and environmental reasons: lower costs in consequence of weight reduction and transportation, possibility of obtaining thick elements and ease of transportation and assembly $[1,4]$. Rigid polyurethane (PU) foams are highly crosslinked, three-dimensional porous materials with many desirable properties such as low density, low thermal conductivity,

\footnotetext{
*Correspondence: gaoli@caf.ac.cn

${ }^{1}$ Research Institute of Forestry New Technology, Chinese Academy of Forestry, No. 1 Dongxiaofu, Haidian District, Beijing 100091, China Full list of author information is available at the end of the article
}

high strength-to-weight ratio and moisture resistance [5]. They are widely used in applications that include insulation, construction, decoration, and automotive parts $[6$, 7]. A typical rigid PU foam formulation mainly includes diisocyanate, polyols, blowing agent, catalyst and surfactant [8]. The PU foam is synthesized by the exothermic reaction of polyols with diisocyanates in addition to a mixture of additives [9].

As a hybrid lightweight composite, wood-polyurethane (W-PU) foam is usually produced through interaction between polyols and isocyanate with wood particles as the filler or reinforced component [10]. Incorporating wood into PU has many advantages. The overall cost of the W-PU could be reduced due to the wide availability and low cost of wood particles which are commonly obtained from wood residues [11]. In addition, wood
Springer Open (c) The Author(s) 2020. This article is licensed under a Creative Commons Attribution 4.0 International License, which permits use, sharing, adaptation, distribution and reproduction in any medium or format, as long as you give appropriate credit to the original author(s) and the source, provide a link to the Creative Commons licence, and indicate if changes were made. The images or other third party material in this article are included in the article's Creative Commons licence, unless indicated otherwise in a credit line to the material. If material is not included in the article's Creative Commons licence and your intended use is not permitted by statutory regulation or exceeds the permitted use, you will need to obtain permission directly from the copyright holder. To view a copy of this licence, visit http://creativeco mmons.org/licenses/by/4.0/. 
incorporation would decrease the environmental impact after disposal for the PU products attributed to its susceptibility to fungal attack [12].

Due to the presence of hydroxyl $(\mathrm{OH})$ groups, wood fillers react with the isocyanate, and thus acceptable foams can be prepared. Yuan and Shi [12] fabricated rigid PU foams containing up to $20 \%$ (in relation to the polyols mass) wood flour. Results showed that the mechanical strength of W-PU foam decreased as the wood flour content increased, even though the density was increased slightly. Delucis et al. [11] studied PU foams filled with up to $10 \%$ (in relation to the overall mass) fillers from forestry wastes, and found that incorporation of $1 \%$ and $5 \%$ wood were the most effective among the studied compositions, with better mechanical performance. Mosiewicki et al. [13] also found that compression modulus and yield strength of PU foams decreased as wood flour content increased to $15 \%$. Generally, the thermal stability and thermal conductivities of the PU foam was improved by the addition of wood. However, the mechanical properties decreased with the increase of wood content, which was probably attributed to their low affinity in the PU system, nucleation phenomenon and weak urethane linkages $[13,14]$.

As the most abundant renewable aromatic polymer that comprises one of the major components in cell walls of lignocellulosic biomass, lignin is a potential bio-based alternative to petroleum-based polyols in the production of PU foams due to its low cost, wide availability, renewability, reactive functional groups and favourable stiffness [15-17]. Lignin contains both phenolic and aliphatic $\mathrm{OH}$ groups in its structure, which provides good reacting sites towards isocyanates [18]. Lignin can be extracted from its botanical source in analytical scale process, but also readily available as a by-product from paper pulping process, which results in technical lignin [19]. Most of the technical lignins are generated by kraft pulping process [20]. Traditionally, kraft lignin is burned to provide energy for the pulp mills, but are rarely used in rather high value-added applications such as chemical or material production [21]. Some attempts have been made to use kraft lignin as a polyol macromonomer for the synthesis of PU. Kraft lignin was first combined with polyether triol and polymeric diphenylmethane diisocyanate (pMDI) to synthesize PU films and it was found that lignin contributed effectively to form a cross-linked network [22]. Li and Ragauskas [23] replaced varying contents of commercial polyols with oxypropylated kraft lignin and synthesized lignin-based rigid PU foams. The generated foams showed typical linkages of PU and superior compressive property than its commercial counterparts, due to the rigidity of aromatic structure in lignin and the high functionality of lignin $\mathrm{OH}$ groups.
Compared to chemical functionalization approach, utilizing technical lignin without any chemical modification is more economically and environmentally favourable. Several studies have been made to replace the petroleumbased polyols with various types of unmodified industrial lignin (e.g. organosolv, kraft, and alkaline lignin), but in some cases it has been at the expense of mechanical properties of PU foams [24, 25]. The main challenge for direct incorporation of lignin in PU system is its aggregation and poor solubility of lignin in the polyol $[9,26]$. In order to improve the dispersion and miscibility of lignin in polyol, Hayati et al. [27] dispersed kraft lignin in polyol at a temperature close to the softening point of lignin by simple mechanical mixing. It was found that heating the polyol/lignin dispersions at $120^{\circ} \mathrm{C}$ enhanced the disaggregation of lignin at loadings of up to $5 \mathrm{wt} \%$. As a result, the compressive strength and thermal insulation of PU foams were simultaneously improved compared to the control without lignin. In summary, previous studies have revealed that lignin played the role like a cross-linking agent for PU foams and was chemically crosslinked not just physically trapped in the PU foams [23, 24, 28]. Moreover, its natural properties also contribute to an improvement of water resistance, antioxidant properties and thermal stabilities of PU foams [26, 29, 30]. Currently, to the best of our knowledge, there are few reports on W-PU composite foams prepared with lignin-containing polyols. Whether the use of lignin can result in the composites with comparable or even superior properties as compared to the conventional polyols is unclear.

The objective of this study was to evaluate kraft lignin to replace polyol for the preparation of rigid W-PU composite foam. W-PU composite foams containing $30 \mathrm{wt} \%$ wood particles were prepared. Regarding the potential reinforcement effect of lignin and its natural compatibility with wood, industrial kraft lignin was used as a biopolyol to substitute $5-20 \%$ of DEG. In order to enhance the disaggregation and miscibility, lignin was dispersed in DEG through vigorous mechanical mixing at high temperature. The lignin-containing PU foams without wood were prepared as reference. The effects of lignin on the preparation and properties (morphology, density, water absorption, compressive properties, and thermal stability) of PU and W-PU foams were examined. Incorporation of inexpensive wood residues and technical lignin can not only broaden their value-added utilization, but also reduce the costs of final PU foam products.

\section{Experimental section \\ Materials}

Poplar (Populus tomentosa Carr.) particles were supplied by Ningfeng Wood-based Panels Co., Ltd. (Lianyungang, China) and sifted to $60 \sim 80$ mesh. Commercial softwood 
kraft lignin (Indulin AT) powder with purity of $93.5 \%$ was provided by MeadWestvaco (USA). Its weight average molar mass $\left(M_{\mathrm{w}}\right)$ was reported as $2700 \mathrm{~g} / \mathrm{mol}$ [15]. The wood particles and lignin powder were dried prior to use.

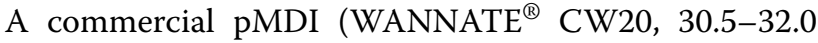
wt\% NCO) was received from Wanhua Chemical Co., Ltd. (Yantai, China). Its viscosity was $150-250 \mathrm{mPa} \cdot \mathrm{s}$ at $25^{\circ} \mathrm{C}$. DEG and polyethylene glycol (PEG) with a $M_{\mathrm{w}}$ of $400 \mathrm{~g} / \mathrm{mol}$, both purchased from Sinopharm Chemical Reagent Co., Ltd. (Shanghai, China), were used as polyols. Dibutyltin dilaurate was purchased from Xiya Chemical Industry Co., Ltd (Shandong, China) and used as the catalyst. Polydimethyl siloxane fluid was purchased from Fuchen Chemical Reagent Co., Ltd (Tianjin, China) and used as the surfactant. All the chemical reagents were of analytical grade and used as received. Water was used as a chemical blowing agent, which could react with isocyanate, generating carbon dioxide.

\section{${ }^{31} \mathrm{P}$ nuclear magnetic resonance (NMR) characterization of lignin}

The ${ }^{31} \mathrm{P}$ NMR spectrum of the lignin sample was collected using a Bruker AVIII $400 \mathrm{MHz}$ NMR spectrometer (Germany). The sample was subjected to phosphitylation following a published method [31]. Briefly, $20 \mathrm{mg}$ of pre-dried lignin was dissolved in a solution of pyridine/deuterated chloroform $\left(\mathrm{CDCl}_{3}\right)$ $(1.6 / 1 \mathrm{v} / \mathrm{v})$. Then, cholesterol (internal standard) and chromium acetylacetonate (relaxation agent) were added, followed by adding 2-chloro-4,4,5,5-tetramethyl-1,3,2-dioxaphospholane (TMDP) as a phosphitylating reagent. Then the mixture was shaken for $10 \mathrm{~min}$ to ensure thorough mixing and reaction. The ${ }^{31} \mathrm{P}$ NMR experiment was carried out with a 5-s relaxation delay and 2048 scans at room temperature.

\section{Preparation of foams}

Prior to making the foam, the lignin powder was dispersed in the DEG at a concentration of 5, 10, 15 and 20\% and stirred rapidly at $120{ }^{\circ} \mathrm{C}$ for $2 \mathrm{~h}$ to obtain the lignin/ DEG dispersions with varying lignin contents. To ensure the completion of the reaction, the $\mathrm{NCO} / \mathrm{OH}$ ratio of 1.1 was used. The amount of lignin, DEG, PEG and pMDI were determined based on the desired lignin contents, $\mathrm{NCO} / \mathrm{OH}$ ratio, $\mathrm{NCO}$ content of $\mathrm{pMDI}$, and $\mathrm{OH}$ groups amount in lignin and polyols. The foams were prepared by a one-shot method according to the formulations listed in Table 1.

First, the lignin/DEG dispersion, PEG, catalyst, surfactant, and blowing agent were weighed out in the required proportions into a plastic cup and mechanically stirred at $300 \mathrm{rpm}$ for $30 \mathrm{~s}$ to obtain a homogeneous mixture. For W-PU composites, the wood particles were added and manually mixed for $1 \mathrm{~min}$. Afterwards, pre-determined pMDI was added and the resultant mixture was vigorously stirred for $15 \mathrm{~s}$ at room temperature, quickly transferred into an open mould and allowed to rise freely owing to the self-generated heat. All the foam samples were left for $48 \mathrm{~h}$ at ambient conditions for curing prior to further characterization. The obtained PU foams containing $0,5,10,15$ and $20 \mathrm{wt} \%$ (based on DEG mass) kraft lignin were prepared and designated as $\mathrm{PU}$ series (PU, PU/L5, PU/L10, PU/L15 and PU/L20). The corresponding $\mathrm{W}-\mathrm{PU}$ composites containing varying contents of lignin were designated as W-PU series (W$\mathrm{PU}, \mathrm{W}-\mathrm{PU} / \mathrm{L} 5, \mathrm{~W}-\mathrm{PU} / \mathrm{L} 10, \mathrm{~W}-\mathrm{PU} / \mathrm{L} 15$ and W-PU/ L20).

\section{Characterization of foams}

The reactivity of foam formulations was measured in a foam cup test according to ASTM D7487, which includes the cream time, gel time, free rise time and tack-free time.

Table 1 Nomenclature and compositions of rigid PU and W-PU foams containing varying lignin contents (parts by weight)

\begin{tabular}{|c|c|c|c|c|c|c|c|c|}
\hline Sample & Lignin & DEG & PEG & Catalyst & Surfactant & Blowing agent & Wood particles & pMDI \\
\hline PU & 0 & 100 & 10 & 2 & 2 & 1.5 & - & 240 \\
\hline PU/L5 & 5 & 95 & 10 & 2 & 2 & 1.5 & - & 232 \\
\hline PU/L10 & 10 & 90 & 10 & 2 & 2 & 1.5 & - & 224 \\
\hline PU/L15 & 15 & 85 & 10 & 2 & 2 & 1.5 & - & 216 \\
\hline PU/L20 & 20 & 80 & 10 & 2 & 2 & 1.5 & - & 208 \\
\hline W-PU & 0 & 100 & 10 & 2 & 2 & 1.5 & 150 & 240 \\
\hline W-PU/L5 & 5 & 95 & 10 & 2 & 2 & 1.5 & 150 & 232 \\
\hline W-PU/L10 & 10 & 90 & 10 & 2 & 2 & 1.5 & 150 & 224 \\
\hline W-PU/L15 & 15 & 85 & 10 & 2 & 2 & 1.5 & 150 & 216 \\
\hline W-PU/L20 & 20 & 80 & 10 & 2 & 2 & 1.5 & 150 & 208 \\
\hline
\end{tabular}


FTIR spectra of the foam samples were determined using a Nicolet IS10 FTIR Spectrometer (Thermo Fisher Scientific, Germany). Each spectrum was collected for the wavelength range of $4000-400 \mathrm{~cm}^{-1}$ at a resolution of $4 \mathrm{~cm}^{-1}$ with 64 scans. Data processing was performed using Omnic v.9.2 software (Thermo Fisher Scientific).

The morphology of the foam cross sections was observed perpendicular to the direction of foam rise using a VHX-6000 digital microscope (KEYENCE, Japan) at 25 times magnification.

The density of foams was determined on compressive test specimens and calculated as the mass-to-volume ratio, with average values of six specimens per sample reported. The compressive properties of the foams were measured using an Instron 5582 universal testing machine (USA) according to ASTM D1621. Specimens with a size of $50 \times 50 \times 25 \mathrm{~mm}^{3}$ were tested in orientation perpendicular to the foam rise direction. The stressstrain curves were recorded at a crosshead speed of $2.5 \mathrm{~mm} / \mathrm{min}$. The load was applied until the foam was compressed to approximately $13 \%$ of its original thickness. The compressive strength was determined at $10 \%$ deformation or at the yield point if a yield point occurred before $10 \%$ deformation. Six specimens were tested for each sample and the results were averaged.

The water absorption of the foams was performed on cubic specimens ( $25 \mathrm{~mm}$ sides) with at least six replicates. Specimens were dipped in de-ionized water for 20 days at room temperature. The sample was taken out of water at specified time intervals, surface water wiped and weighed. The water absorption of samples was reported as weight percentage gain.

Thermal gravimetric analysis (TGA) was carried out using a NETZSCH STA 449 F3 instrument. Small pieces of foam (approximately $10 \mathrm{mg}$ ) were analysed for weight loss in platinum pans in flowing nitrogen atmosphere $(30 \mathrm{~mL} / \mathrm{min})$. The samples were heated at a rate of $10{ }^{\circ} \mathrm{C} /$ $\min$ to $750{ }^{\circ} \mathrm{C}$.

\section{Statistical analysis}

The statistical variation between different sample groups for specific compressive properties were analysed and compared by analysis of variance (ANOVA) using the IBM $^{\circledR}$ SPSS Statistics v.19 software. Prior to analysis, the homogeneity of variances was checked using Levene test. A one-way ANOVA was performed to analyse the significance of difference among the groups using a Tukey test at a confidence level of $95 \%(p<0.05)$.

\section{Results and discussion}

Quantitative ${ }^{31} \mathrm{P}$ NMR analysis of lignin

${ }^{31} \mathrm{P}$ NMR analysis was applied in order to quantitatively evaluate the content of $\mathrm{OH}$ groups in lignin. The ${ }^{31} \mathrm{P}$

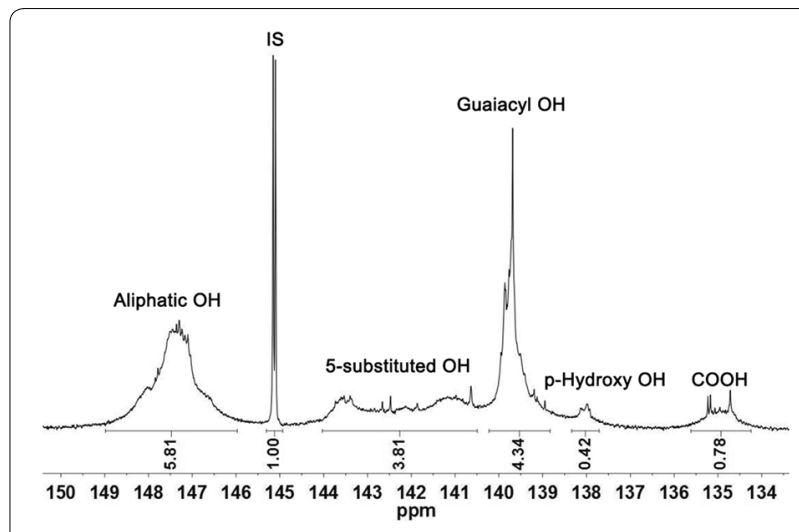

Fig. 1 Quantitative ${ }^{31}$ P NMR spectrum of softwood kraft lignin

Table 2 Foaming characteristic times of the PU and W-PU foams containing varying contents of lignin

\begin{tabular}{lcccc}
\hline Sample & Cream time (s) & Gel time (s) & $\begin{array}{l}\text { Free rise } \\
\text { time }(\mathbf{s})\end{array}$ & $\begin{array}{l}\text { Tack-free } \\
\text { time (s) }\end{array}$ \\
\hline PU & 34 & 58 & 84 & 324 \\
PU/L5 & 81 & 108 & 134 & 378 \\
PU/L10 & 100 & 145 & 186 & 431 \\
PU/L15 & 102 & 146 & 191 & 455 \\
PU/L20 & 105 & 148 & 200 & 483 \\
W-PU & 133 & 179 & 227 & 367 \\
W-PU/L5 & 160 & 196 & 270 & 405 \\
W-PU/L10 & 199 & 237 & 326 & 432 \\
W-PU/L15 & 204 & 277 & 364 & 479 \\
W-PU/L20 & 228 & 282 & 432 & 517 \\
\hline
\end{tabular}

NMR spectrum of phosphitylated lignin with chemical shift assignments is shown in Fig. 1. The obtained spectrum showed well-resolved signals for aliphatic $\mathrm{OH}$ (146-149 ppm), phenolic 5-substituted OH (140.5$144.5 \mathrm{ppm})$, guaiacyl $\mathrm{OH}$ (138.5-140.5 ppm), $p$-hydroxy $\mathrm{OH}(137.5-138.5 \mathrm{ppm})$ and carboxylic acid (134.2$135.5 \mathrm{ppm}$ ) groups present in lignin [32, 33]. Based on the integration area and amount of internal standard, the total $\mathrm{OH}$ groups content was determined to be $4.99 \mathrm{mmol} / \mathrm{g}$ ( $\mathrm{mmol}$ of $\mathrm{OH}$ group per g dry lignin). The content of $\mathrm{OH}$ groups is similar to the data in the literature for softwood kraft lignin, with total aliphatic and phenolic $\mathrm{OH}$ value of $4.89 \mathrm{mmol} / \mathrm{g}$ being reported [32]. The results provided fundamental information for calculating the desired amount of raw material.

\section{Reactivity of foam formulations}

The cream time, gel time, free rise time and tack-free time during the free rise foaming process are recorded in Table 2. The foaming reaction rate was lower as wood particles were introduced, probably due to the steric 
hindrance effects of wood OH groups [13]. Incorporation of lignin decreased the reactivity of the system. As the amount of lignin increased and the amount of DEG decreased, the reactivity decreased further, implying the active interaction of the more miscible lignin content with the pMDI [27]. The slower foaming behaviour could be caused by the increased viscosity of the lignin/ DEG dispersion. Furthermore, increased lignin content brought higher proportion of phenolic $\mathrm{OH}$ groups whose reactivities with isocyanates were lower than aliphatic $\mathrm{OH}$ groups [27].

\section{FTIR analysis of lignin and foams}

Figure 2 shows the FTIR spectra of the kraft lignin and lignin-containing PU foams. The characteristic bands of guaiacyl units at 1270 and $1032 \mathrm{~cm}^{-1}$ were present in the softwood kraft lignin, while the bands of 1330 and $1117 \mathrm{~cm}^{-1}$ related to syringyl units were absent. Figure 3 shows the FTIR spectra of lignin-containing W-PU foams. FTIR analysis confirmed the presence of urethane linkages characteristic for all the foam samples. The absorption band at $3330 \mathrm{~cm}^{-1}$ is related to $\mathrm{N}-\mathrm{H}$ stretching vibration [33]. It was noted that lignin-containing PU and W-PU samples presented peak at $2273 \mathrm{~cm}^{-1}$, which corresponded to unreacted NCO groups. Incorporating more lignin showed increase in this band intensity, indicating that the reactivity in our formulation was decreased with increasing lignin content. The band at $1702 \mathrm{~cm}^{-1}$ is assigned the characteristic $\mathrm{C}=\mathrm{O}$ vibration, which are the essential carbon structure of polyurethane foam [34]. The other characteristic bands include $\mathrm{N}-\mathrm{H}$ bending vibration $\left(1510 \mathrm{~cm}^{-1}\right), \mathrm{C}-\mathrm{N}$ stretching $\left(1217 \mathrm{~cm}^{-1}\right)$, and $\mathrm{C}-\mathrm{O}$ stretching $\left(1065 \mathrm{~cm}^{-1}\right)$ [11]. All the samples exhibited these features, which indicated

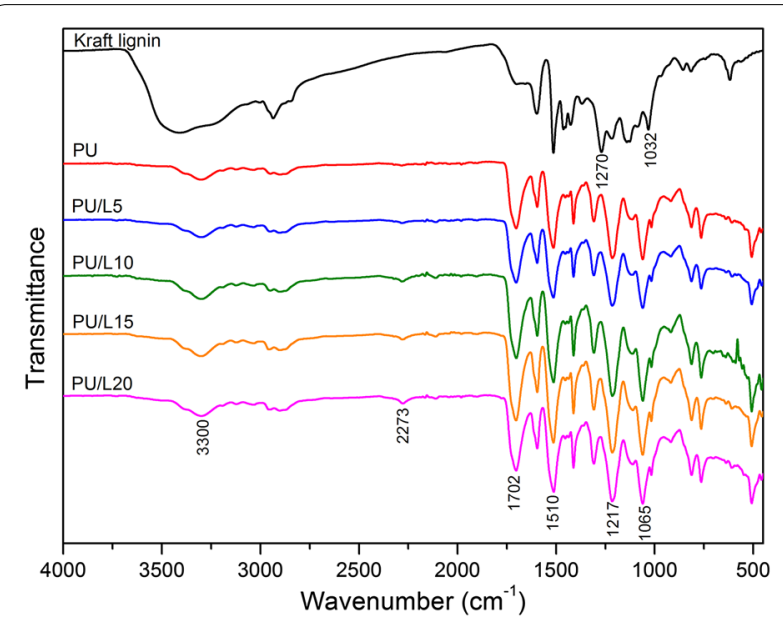

Fig. 2 FTIR spectra of the PU foams containing varying contents of lignin

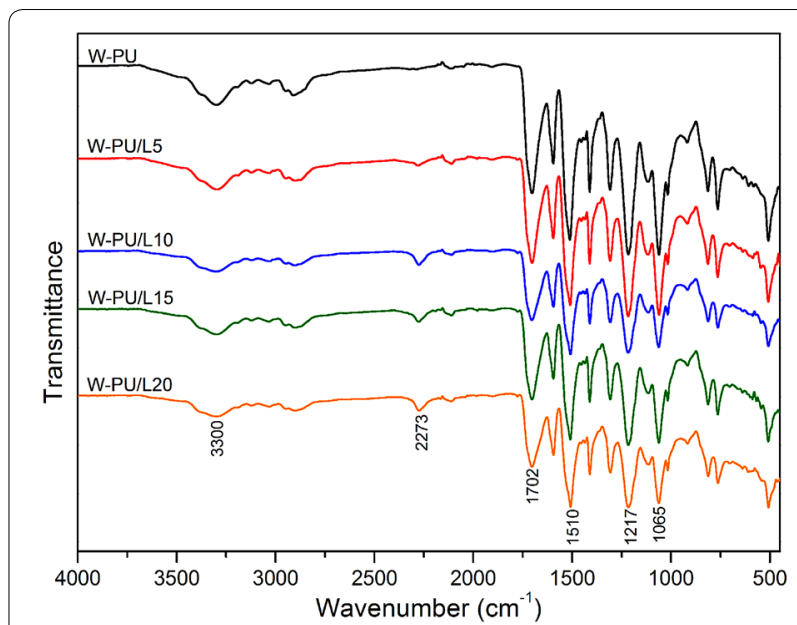

Fig. 3 FTIR spectra of the W-PU foams containing varying contents of lignin

the occurrence of chemical reaction between isocyanate groups $(\mathrm{N}=\mathrm{C}=\mathrm{O})$ of pMDI and $\mathrm{OH}$ groups of polyol, lignin, and wood.

\section{Foam morphology}

Since foam morphology has a significant influence on physical and mechanical properties of the PU samples, the transmission optical micrographs of the foams cut perpendicular to the blowing direction are shown in Fig. 4. The cell surface of the neat PU sample was mostly regular and smooth. With the incorporation of lignin, the foam had dark colour and the cellular shape became irregular with formation of large cells. It was found that PU/L15 and PU/L20 samples exhibited agglomerates of lignin (darker areas) in their cell structure. The alteration in cell morphology was probably related with the increased viscosity of reaction mixture and self-association of the lignin polymer, as a result, the formation and growth of bubbles were suppressed leading to heterogeneity of the morphology of the foam [34]. Compared to the PU series, the overall cell shape of W-PU series became more irregular. All the W-PU samples presented poor cellular structures with a larger number of open cells. This effect was also reported in previous study and probably attributed to the attachment of particles to the cell wall, weakening the cell structure, and ultimately leading to rupture of cells [11].

\section{Density}

Effect of lignin content on the density of PU and WPU foams is illustrated in Table 3. The average density of the reference PU foam was $62 \mathrm{~kg} / \mathrm{m}^{3}$. An increase of density was observed upon replacing $5-20 \%$ of DEG 


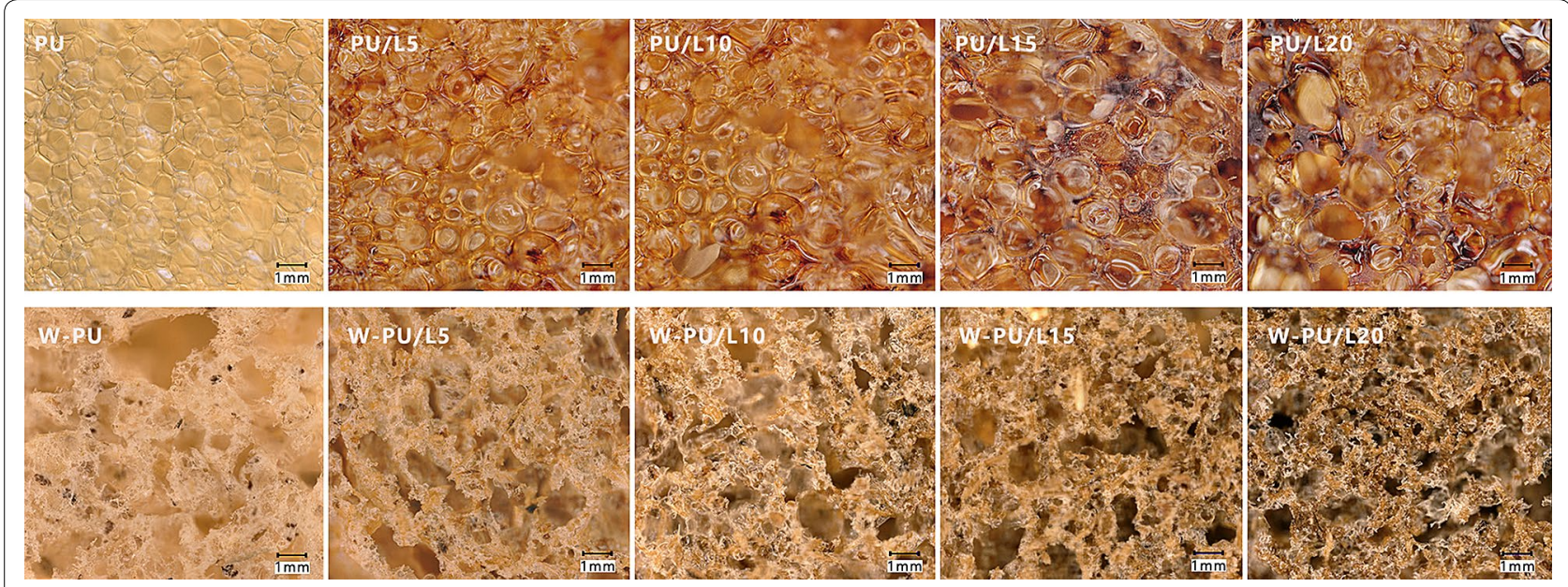

Fig. 4 Morphology of cross section of the PU and W-PU foams containing varying contents of lignin observed perpendicular to foam rise

Table 3 Density and compressive properties of the PU and W-PU foams containing varying contents of lignin perpendicular to foam rise

\begin{tabular}{|c|c|c|c|c|c|}
\hline Sample & Density $\left(\mathrm{kg} / \mathrm{m}^{3}\right)$ & $\begin{array}{l}\text { Compressive } \\
\text { strength (KPa) }\end{array}$ & $\begin{array}{l}\text { Compressive } \\
\text { modulus (MPa) }\end{array}$ & $\begin{array}{l}\text { Specific compressive } \\
\text { strength }\left(\mathrm{MPa} /\left(\mathrm{g} \mathrm{cm}^{-3}\right)\right)\end{array}$ & $\begin{array}{l}\text { Specific compressive } \\
\text { modulus }(\mathrm{MPa} /(\mathrm{g} \\
\left.\left.\mathrm{cm}^{-3}\right)\right)\end{array}$ \\
\hline PU & $62 \pm 2$ & $330 \pm 17$ & $8.15 \pm 1.30$ & $4.63 \pm 0.31$ & $90.3 \pm 4.6$ \\
\hline PU/L5 & $100 \pm 7$ & $728 \pm 35$ & $10.07 \pm 0.89$ & $7.16 \pm 0.32$ & $114.1 \pm 12.3$ \\
\hline PU/L10 & $108 \pm 7$ & $690 \pm 48$ & $10.39 \pm 1.88$ & $5.83 \pm 0.85$ & $119.7 \pm 7.2$ \\
\hline PU/L15 & $111 \pm 3$ & $658 \pm 52$ & $10.54 \pm 1.21$ & $4.99 \pm 0.48$ & $102.6 \pm 7.4$ \\
\hline PU/L20 & $115 \pm 4$ & $642 \pm 71$ & $14.72 \pm 2.86$ & $4.26 \pm 0.46$ & $80.4 \pm 4.9$ \\
\hline W-PU & $47 \pm 4$ & $56 \pm 8$ & $0.74 \pm 0.07$ & $1.08 \pm 0.17$ & $12.8 \pm 2.2$ \\
\hline W-PU/L5 & $52 \pm 3$ & $62 \pm 2$ & $0.95 \pm 0.08$ & $1.10 \pm 0.05$ & $16.0 \pm 1.2$ \\
\hline W-PU/L10 & $72 \pm 1$ & $84 \pm 5$ & $1.16 \pm 0.01$ & $1.23 \pm 0.16$ & $16.6 \pm 1.3$ \\
\hline W-PU/L15 & $84 \pm 6$ & $98 \pm 14$ & $1.73 \pm 0.04$ & $1.25 \pm 0.03$ & $19.2 \pm 2.2$ \\
\hline W-PU/L20 & $96 \pm 5$ & $113 \pm 8$ & $2.16 \pm 0.10$ & $1.68 \pm 0.19$ & $19.0 \pm 1.1$ \\
\hline
\end{tabular}

with lignin. This was probably due to the relatively lower $\mathrm{OH}$ reactivity of lignin, which resulted in a slower gelation reaction with the increased lignin content. A slower gelation reaction rate led to more gases escaping from the foam structure and hence smaller void volumes and higher densities [33]. The density of W-PU samples ranged from 47 to $96 \mathrm{~kg} / \mathrm{m}^{3}$ upon incorporating 5-20\% lignin, retaining an acceptable density. Interestingly, in comparison of PU and W-PU samples with the same lignin content, a relatively lower density was obtained in the W-PU samples. A potential reason for this phenomenon was that incorporation of both wood particles and lignin increased the percent of heterogeneous cells and the reaction time that could generate more gases during the reaction [33].

\section{Compressive properties of foams}

Compressive properties are the major parameters that reflect the firmness of PU foam, which is one of the most important characteristics of the foams together with density [33]. Compressive strength and modulus of the PU and $\mathrm{W}-\mathrm{PU}$ foams containing varying contents of lignin are tabulated in Table 3. Both the compressive strength and modulus increased upon the incorporation of lignin. The compressive properties of PU foam samples depend considerably on their densities and cellular structure morphology [35]. Generally, the compressive strength and modulus of lignin-containing PU and W-PU foams had a positive correlation with their densities.

As shown in Table 3, the apparent density of the samples varied with lignin content and presence of wood particles. Hence, the specific compressive strength $\left(\sigma_{\rho}\right)$ and modulus $\left(E_{\rho}\right)$ (i.e. dividing the compressive strength and 
modulus of each specimen by its respective density) were used to further clarify the effect of lignin on the compressive properties of foams. The addition of lignin had a significant effect on the specific compressive properties of PU and W-PU samples. For PU series, incorporation of $5 \%$ and $10 \%$ lignin resulted in a statistically significant increase in $\sigma_{\rho}$ and $E_{\rho}$ compared to the neat PU (Fig. 5). This improvement could be attributed to the greater cross-linking density of the foams due to incorporation of lignin [28]. Further increase in lignin amount (10 to 15\%) led to a decrease in $\sigma_{\rho}$ and $E_{\rho}$. The decline in $\sigma_{\rho}$ and $E_{\rho}$ was probably attributed to the agglomeration and aggregation of lignin in the foam (Fig. 4), which was likely to occur at high lignin contents. Previous study by Hayati et al. [27] also reported the increase in specific compressive strength of $\mathrm{PU}$ foams with lignin incorporation up to $5 \%$. For W-PU series, both $\sigma_{\rho}$ and $E_{\rho}$ slightly increased with the increasing lignin content (Fig. 6). The $\sigma_{\rho}$ increased by $55 \%$ from $1.08 \mathrm{MPa} /\left(\mathrm{g} \mathrm{cm}^{-3}\right)$ to $1.68 \mathrm{MPa} /$ $\left(\mathrm{g} \mathrm{cm}^{-3}\right.$ ) with lignin content from 0 to $20 \%$, and the $E_{\rho}$ increased by $48 \%$ from $12.8 \mathrm{MPa} /\left(\mathrm{g} \mathrm{cm}^{-3}\right)$ to $19.0 \mathrm{MPa} /(\mathrm{g}$ $\mathrm{cm}^{-3}$ ). The improvement of $\sigma_{\rho}$ and $E_{\rho}$ over the lignin content $(0-20 \%)$ suggested substituting partial polyol with lignin enhanced the rigidity of $\mathrm{W}-\mathrm{PU}$ foams.

\section{Water absorption of foams}

During immersion in water, the water absorption of the foams was evaluated by the weight percentage gain (Fig. 7). There was a rapid rise of the water absorption along the first $24 \mathrm{~h}$, followed by a gradual stabilization. In general, the PU series achieved a saturated state of water uptake within 10 days, whereas the $\mathrm{W}-\mathrm{PU}$ series samples took longer. The neat PU foam sample presented a saturated water absorption of approximately

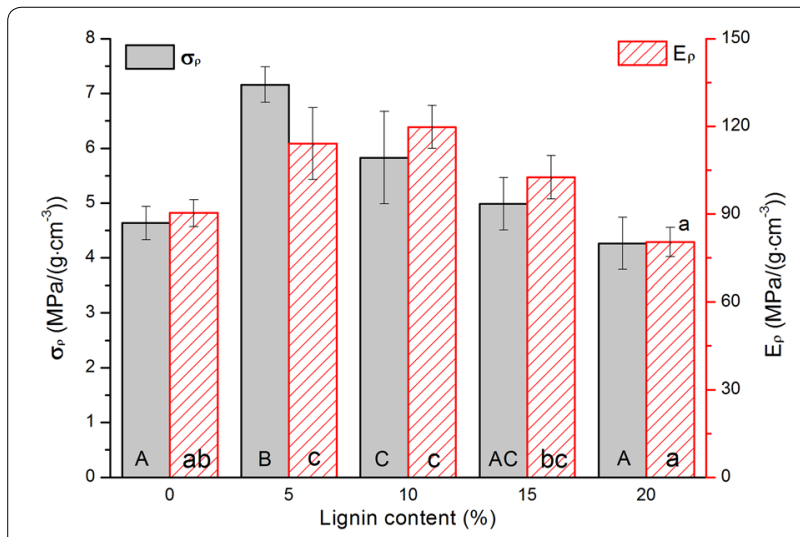

Fig. 5 Specific compressive strength $\left(\sigma_{\rho}\right)$ and modulus $\left(E_{\rho}\right)$ of the $\mathrm{PU}$ foams containing varying contents of lignin perpendicular to foam rise. Different letters represent statistically significant difference between groups $(p<0.05)$

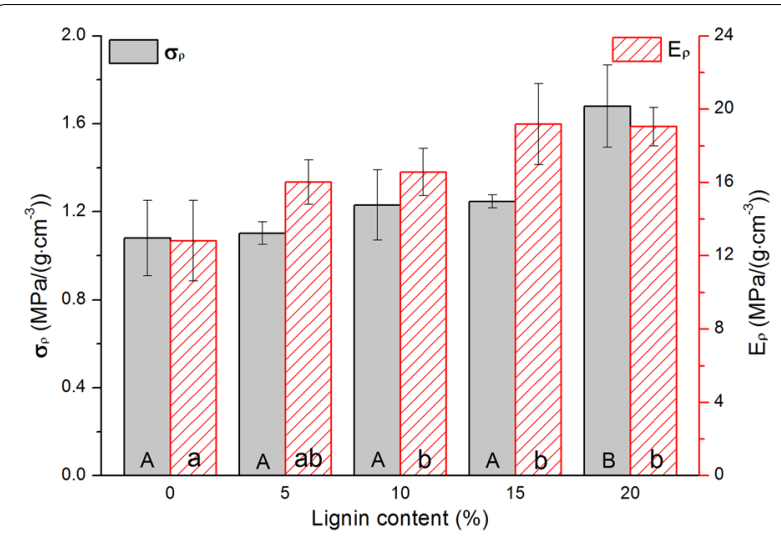

Fig. 6 Specific compressive strength $\left(\sigma_{\rho}\right)$ and modulus $\left(E_{\rho}\right)$ of the W-PU foams containing varying contents of lignin perpendicular to foam rise. Different letters represent statistically significant difference between groups $(p<0.05)$

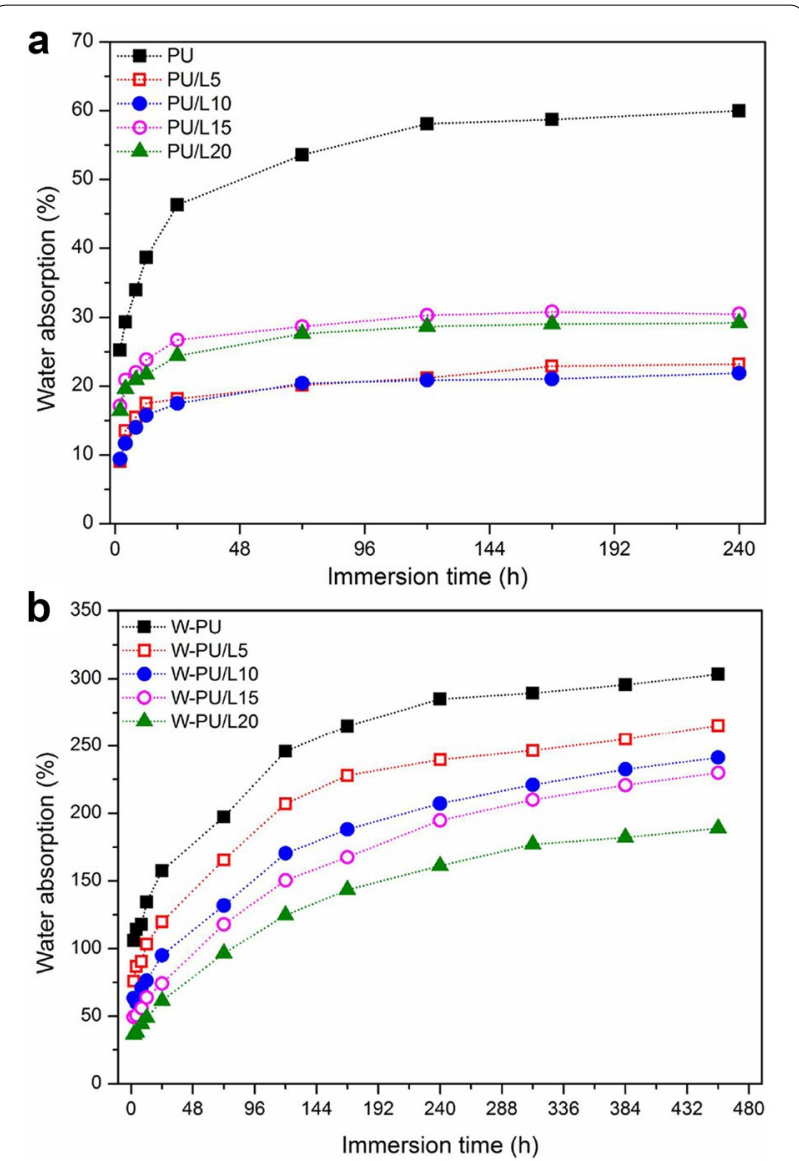

Fig. 7 Water absorption kinetic of $\mathbf{a}$ PU series and $\mathbf{b}$ W-PU series foams containing varying amounts of lignin 
60\%. Previous study by Delucis et al. [11] reported similar water uptake level of $65 \%$. Since lignin is relatively hydrophobic, replacing a portion of hydrophilic polyol with lignin reduced the water absorption of the resultant foams compared with neat PU. The PU/L15 and PU/L20 samples exhibited higher water absorption than PU/L5 and PU/L10 samples. Previous literature reported that the cell structure influenced the water absorption capability of the PU foams, and larger cells would be able to accommodate more water [36]. The presence of more large cells with increasing lignin amounts contributed to higher water absorption. WPU samples exhibited much higher water absorption than PU samples. This phenomenon was probably due to the hydrophilic characteristic of wood particles and the poor cellular structure of W-PU samples with lots of voids that hold more water inside. For W-PU series, the water absorption generally decreased with increasing lignin content as well. When DEG was replaced by lignin at $20 \%$, the water absorption for W-PU foam was reduced by $38 \%$.

\section{Thermal stability of foams}

Thermogravimetric analysis was conducted to evaluate the influence of lignin on the thermal stability of PU and W-PU foams. Thermogravimetric (TG) and derivative thermogravimetric (DTG) curves of the foams are shown in Fig. 8. All the foam samples were degraded in a broad temperature range of $200-600{ }^{\circ} \mathrm{C}$, with three stages. A small weight loss was observed prior to $250{ }^{\circ} \mathrm{C}$, which was probably due to the degradation of some unreacted small molecules, such as polyol component [33]. The second step occurred in the range of $250-450{ }^{\circ} \mathrm{C}$ at a fast rate, mainly attributed to the decomposition of urethane linkages in the foams [33]. For foams after $450{ }^{\circ} \mathrm{C}$, a slow weight loss was presented, and is related to other remaining structures formed after the second degradation step, such as diisocyanate and lignin aromatic rings [37].
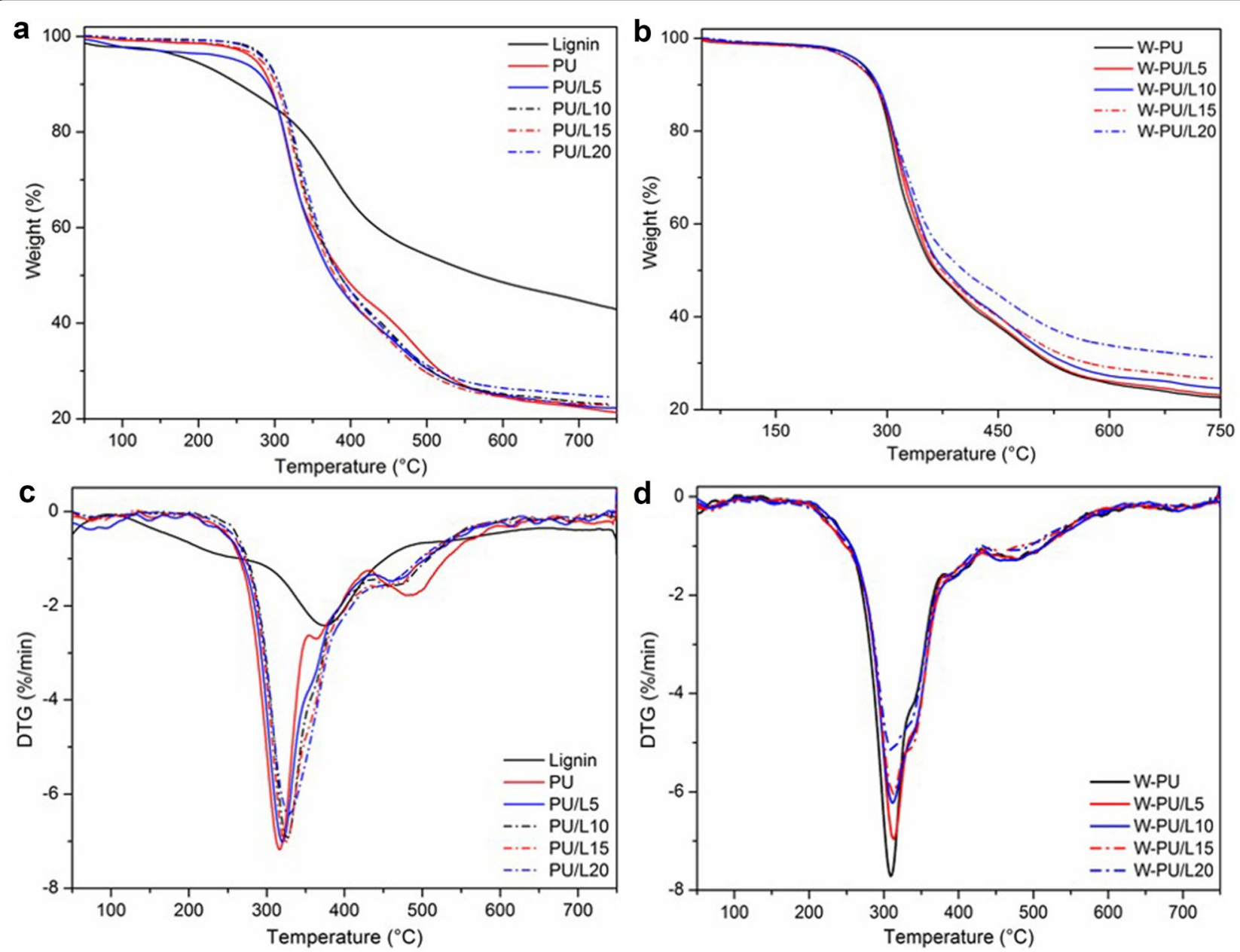

Fig. 8 a, b TG and $\mathbf{c}$, d DTG curves of the PU and W-PU foams with varying lignin contents 
The thermogravimetric parameters, including initial decomposition temperature $\left(T_{0}\right)$, maximum decomposition temperature $\left(T_{\max }\right)$, temperature for $50 \%$ mass loss $\left(T_{50 \%}\right)$ and char residue at $750{ }^{\circ} \mathrm{C}$ are listed in Table 4. Lignin incorporation slightly decreased the $T_{0}$ and increased $T_{\max }$ for both PU and W-PU samples. The char residue is a critical factor in flame retardant performance during combustion [38]. The addition of lignin did not significantly affect the thermal degradation behaviour, but it rather increased the char yield due to lignin aromatic chemical structure [38]. It was found that the lignin addition increased the char yield of lignin-containing PU and W-PU samples. As the lignin content increased from 0 to $20 \%$, the char residue of $\mathrm{W}-\mathrm{PU}$ increased from 22.7 to $31.3 \%$, while the $T_{50 \%}$ shifted to higher temperature. These results indicated that thermal stability of the foams was enhanced by using lignin as bio-polyol.

\section{Conclusions}

This paper reports an efficient and simple methodology for improving the performance of W-PU hybrid foam (containing $30 \mathrm{wt} \%$ wood particles) via addition of kraft lignin without any chemical modification. The lignin was incorporated up to $20 \mathrm{wt} \%$ as bio-polyol into the DEG by simple mechanical mixing at $120^{\circ} \mathrm{C}$ for $2 \mathrm{~h}$, and then the mixture was blended with PEG, wood particles and other components to react with pMDI for preparing W-PU foams. FTIR analysis indicated typical peaks for softwood kraft lignin and urethane linkages in foam samples. Compared to neat PU foams, W-PU foams exhibited inhomogeneous cell structure, lower compressive properties and higher water absorption, while replacing partial polyol by kraft lignin improved compressive properties and water resistance of the W-PU foams. The specific compressive strength and modulus of the WPU foams were also improved. Additionally, the thermal

Table 4 Thermogravimetric parameters of PU and W-PU foams containing varying contents of lignin

\begin{tabular}{lllll}
\hline Sample & $T_{0}\left({ }^{\circ} \mathrm{C}\right)$ & $T_{\max }\left({ }^{\circ} \mathrm{C}\right)$ & $T_{50 \%}\left({ }^{\circ} \mathrm{C}\right)$ & Char residue (\%) \\
Lignin & 183.2 & 374.6 & 552.9 & 42.9 \\
$\mathrm{PU}$ & 284.4 & 316.5 & 386.1 & 21.3 \\
$\mathrm{PU} / \mathrm{L} 5$ & 282.1 & 320.3 & 371.5 & 22.3 \\
$\mathrm{PU} / \mathrm{L} 10$ & 278.2 & 323.5 & 381.4 & 22.7 \\
$\mathrm{PU} / \mathrm{L} 15$ & 274.7 & 325.6 & 384.1 & 23.0 \\
$\mathrm{PU} / \mathrm{L} 20$ & 271.7 & 328.4 & 385.9 & 24.6 \\
W-PU & 257.9 & 309.0 & 362.7 & 22.7 \\
W-PU/L5 & 250.8 & 312.9 & 365.5 & 23.2 \\
W-PU/L10 & 249.6 & 311.5 & 371.9 & 24.7 \\
W-PU/L15 & 248.7 & 311.8 & 373.2 & 26.6 \\
W-PU/L20 & 248.2 & 311.0 & 396.7 & 31.3 \\
\hline
\end{tabular}

stability of W-PU foams was slightly improved due to the presence of lignin. The combined application of the lignin and wood particles in the synthesis of PU foam is more advantageous than the addition of only wood particles. This method not only helps to broaden the utilization of technical lignin, but also provides a potential way to prepare lightweight W-PU composites.

\begin{abstract}
Abbreviations
W-PU: Wood-polyurethane; DEG: Diethylene glycol; FTIR: Fourier transform infrared; pMDI: Polymeric diphenylmethane diisocyanate; $M_{w}$ : Weight average molar mass; PEG: Polyethylene glycol; NMR: Nuclear magnetic resonance; $\mathrm{CDCl}_{3}$ : Deuterated chloroform; TMDP: 2-Chloro-4,4,5,5-tetramethyl-1,3,2dioxaphospholane; TGA: Thermal gravimetric analysis; ANOVA: Analysis of variance; DTG: Derivative thermogravimetric.
\end{abstract}

\section{Acknowledgements}

Not applicable.

\section{Authors' contributions}

$S L$ and $L G$ designed and performed the experiments. WG was a major contributor in getting the fund. SL, LG, and WG participated in writing the manuscript. All authors read and approved the final manuscript.

\section{Funding}

This work was financially supported by the National Key Research and Development Program of China "Manufacturing technology of lightweight woodbased material" (2018YFD0600301) and the Special Fund of Chinese Academy of Forestry for Fundamental Scientific Research (CAFYBB2017ZX003-3).

\section{Availability of data and materials}

All data generated or analysed during this study are included in this published article.

\section{Competing interests}

The authors declare that they have no competing interests.

\section{Author details}

${ }^{1}$ Research Institute of Forestry New Technology, Chinese Academy of Forestry, No. 1 Dongxiaofu, Haidian District, Beijing 100091, China. ${ }^{2}$ Research Institute of Wood Industry, Chinese Academy of Forestry, No. 1 Dongxiaofu, Haidian District, Beijing 100091, China.

Received: 18 January 2020 Accepted: 27 March 2020

Published online: 02 April 2020
References

1. Monteiro S, Martins J, Magalhães FD, Carvalho L (2018) Lightweight wood composites: challenges, production and performance. In: Kalia S (ed) Lignocellulosic Composite Materials, vol 1. Springer, Cham, pp 293-322

2. Monteiro S, Martins J, Magalhães F, Carvalho L (2016) Low density wood-based particleboards bonded with foamable sour cassava starch: preliminary studies. Polymers 8(10):354

3. Shalbafan A, Welling J, Luedtke J (2013) Effect of processing parameters on physical and structural properties of lightweight foam core sandwich panels. Wood Mater Sci Eng 8(1):1-12

4. Monteiro S, Martins J, Magalhaes FD, Carvalho L (2019) Low density wood particleboards bonded with starch foam-study of production process conditions. Materials 12(12):1975

5. Kairytė A, Kirpluks M, Ivdre A, Cabulis U, Vejelis S, Balčiūnas G (2018) Paper waste sludge enhanced eco-efficient polyurethane foam composites: physical-mechanical properties and microstructure. Polym Compos 39(6):1852-1860 
6. Chen S, Jiang Y (2018) The acoustic property study of polyurethane foam with addition of bamboo leaves particles. Polym Compos 39(4):1370-1381

7. Kausar A (2017) Polyurethane composite foams in high-performance applications: a review. Polymer-Plastics Technol Eng 57(4):346-369

8. Chen YC, Tai W (2018) Castor oil-based polyurethane resin for low-density composites with bamboo charcoal. Polymers 10(10):1100

9. Mahmood N, Yuan Z, Schmidt J, Xu C (2016) Depolymerization of lignins and their applications for the preparation of polyols and rigid polyurethane foams: a review. Renew Sustain Energy Rev. 60:317-329

10. Rácz I, Andersen E, Aranguren MI, Marcovich NE (2009) Wood flour-recycled polyol based polyurethane lightweight composites. J Compos Mater 43(24):2871-2884

11. Delucis RdA, Magalhães WLE, Petzhold CL, Amico SC (2018) Forest-based resources as fillers in biobased polyurethane foams. J Appl Polym Sci 135(3):45684

12. Yuan J, Shi SQ (2009) Effect of the addition of wood flours on the properties of rigid polyurethane foam. J Appl Polym Sci 113(5):2902-2909

13. Mosiewicki MA, Dell'Arciprete GA, Aranguren MI, Marcovich NE (2009) Polyurethane foams obtained from castor oil-based polyol and filled with wood flour. J Compos Mater 43(25):3057-3072

14. Gu R, Sain MM, Konar SK (2013) A feasibility study of polyurethane composite foam with added hardwood pulp. Ind Crops Prod 42:273-279

15. Luo S, Cao J, McDonald AG (2018) Cross-linking of technical lignin via esterification and thermally initiated free radical reaction. Ind Crops Prod 121:169-179

16. Xue B-L, Wen J-L, Sun R-C (2015) Producing lignin-based polyols through microwave-assisted liquefaction for rigid polyurethane foam production. Materials 8(2):586-599

17. Matsushita Y (2015) Conversion of technical lignins to functional materials with retained polymeric properties. J. Wood Sci. 61(3):230-250

18. Schorr D, Diouf PN, Stevanovic T (2014) Evaluation of industrial lignins for biocomposites production. Ind Crops Prod 52:65-73

19. Kai D, Tan MJ, Chee PL, Chua YK, Yap YL, Loh XJ (2016) Towards lignin-based functional materials in a sustainable world. Green Chem 18(5):1175-1200

20. Calvo-Flores FG, Dobado JA (2010) Lignin as renewable raw material. Chemsuschem 3(11):1227-1235

21. Duval A, Lawoko M (2014) A review on lignin-based polymeric, microand nano-structured materials. React Funct Polym 85:78-96

22. Yoshida H, Mörck R, Kringstad K, Hatakeyama H (1987) Kraft lignin in polyurethanes I. Mechanical properties of polyurethanes from a kraft ligninpolyether triol-polymeric MDI system. J Appl Polym Sci 34(3):1187-1198

23. Li Y, Ragauskas AJ (2012) Kraft lignin-based rigid polyurethane foam. J Wood Chem Technol 32(3):210-224

24. Pan X, Saddler JN (2013) Effect of replacing polyol by organosolv and kraft lignin on the property and structure of rigid polyurethane foam. Biotechnol Biofuels 6(1):12

25. Xue B-L, Wen J-L, Sun R-C (2014) Lignin-based rigid polyurethane foam reinforced with pulp fiber: synthesis and characterization. ACS Sustain Chem. Eng. 2(6):1474-1480
26. Alinejad M, Henry C, Nikafshar S, Gondaliya A, Bagheri S, Chen N, Singh SK, Hodge DB, Nejad M (2019) Lignin-based polyurethanes: opportunities for bio-based foams, elastomers. Coat Adhes Polym 11(7):1202

27. Hayati AN, Evans DAC, Laycock B, Martin DJ, Annamalai PK (2018) A simple methodology for improving the performance and sustainability of rigid polyurethane foam by incorporating industrial lignin. Ind Crops Prod 117:149-158

28. Luo X, Mohanty A, Misra M (2013) Lignin as a reactive reinforcing filler for water-blown rigid biofoam composites from soy oil-based polyurethane. Ind Crops Prod 47:13-19

29. Mahmood N, Yuan Z, Schmidt J, Xu C (2015) Preparation of bio-based rigid polyurethane foam using hydrolytically depolymerized Kraft lignin via direct replacement or oxypropylation. Eur Polym J. 68:1-9

30. Delucis RdA, Magalhães WLE, Petzhold CL, Amico SC (2018) Thermal and combustion features of rigid polyurethane biofoams filled with four forest-based wastes. Polym Compos 39(S3):E1770-E1777

31. Crestini C, Argyropoulos DS (1997) Structural analysis of wheat straw lignin by quantitative 31P and 2D NMR spectroscopy. The occurrence of ester bonds and a-O-4 substructures. J Agric Food Chem. 45(4):1212-1219

32. Constant $S$, Wienk HLJ, Frissen AE, Peinder Pd, Boelens R, van Es DS, Grisel RJH, Weckhuysen BM, Huijgen WJJ, Gosselink RJA, Bruijnincx PCA (2016) New insights into the structure and composition of technical lignins: a comparative characterisation study. Green Chem 18(9):2651-2665

33. Zhu S, Chen K, Xu J, Li J, Mo L (2018) Bio-based polyurethane foam preparation employing lignin from corn stalk enzymatic hydrolysis residues. RSC Advances 8(28):15754-15761

34. Członka S, Bertino MF, Kośny J, Strąkowska A, Masłowski M, Strzelec K (2018) Linseed oil as a natural modifier of rigid polyurethane foams. Ind Crops Prod 115:40-51

35. Hamilton AR, Thomsen OT, Madaleno LAO, Jensen LR, Rauhe JCM, Pyrz R (2013) Evaluation of the anisotropic mechanical properties of reinforced polyurethane foams. Compos Sci Technol 87:210-217

36. Thirumal M, Khastgir D, Singha NK, Manjunath BS, Naik YP (2008) Effect of foam density on the properties of water blown rigid polyurethane foam. J Appl Polym Sci 108(3):1810-1817

37. Tavares LB, Boas CV, Schleder GR, Nacas AM, Rosa DS, Santos DJ (2016) Bio-based polyurethane prepared from Kraft lignin and modified castor oil. Express Polym Lett. 10(11):927-940

38. Lu W, Li Q, Zhang Y, Yu H, Hirose S, Hatakeyama H, Matsumoto Y, Jin Z (2018) Lignosulfonate/APP IFR and its flame retardancy in lignosulfonatebased rigid polyurethane foams. J Wood Sci. 64(3):287-293

\section{Publisher's Note}

Springer Nature remains neutral with regard to jurisdictional claims in published maps and institutional affiliations.

\section{Submit your manuscript to a SpringerOpen ${ }^{\oplus}$ journal and benefit from:}

- Convenient online submission

- Rigorous peer review

- Open access: articles freely available online

- High visibility within the field

Retaining the copyright to your article

Submit your next manuscript at springeropen.com 